\title{
CONFIGURACIÓN DEL FLÂNEUR EN POETA EN NUEVA YORK DE F. GARCÍA LORCA
}

Configuration of the Flâneur in Poeta en Nueva York by F. García Lorca

René Araya Alarcón*

Resumen

En primer término se analiza brevemente el contexto que posibilita en García Lorca la búsqueda de un nuevo lenguaje poético durante su estadía en Nueva York entre 19291930. Posteriormente se analiza el concepto de flâneur. Para ello se consideran las elaboraciones que desarrolló Walter Benjamin a propósito de la experiencia de Charles Baudelaire frente a las transformaciones urbanas y sociales que sufrió París a mediados del siglo XIX, durante el Segundo Imperio en Francia. Finalmente se indaga en la eventual configuración de la figura del flâneur en Poeta en Nueva York de Federico Garcia Lorca.

Palabras clave: Flâneur, C. Baudelaire, F. García Lorca, Poeta en Nueva York.

\section{Abstract}

First of all, it's analyzed briefly the context that makes possible in García Lorca the search of a new poetic language during his stay in New York between 1929 and 1930. Subsequently it's analyzed the concept of flâneur. Because of that, it must be taken into account the devise that Walter Benjamin explained according to Charles Baudelaire's experience against the urban and social transformations that hit Paris in the $19^{\text {th }}$ century during the Second French Empire. Finally it makes inquiries in the possible configuration of the flâneur in Poeta en Nueva York by Federico García Lorca.

Key words: Flâneur, C. Baudelaire, F. García Lorca, Poeta en Nueva York.

\section{NUEVA YORK EN UN POETA: LA EMERGENCIA DE UN LENGUAJE}

Entre 1929 y 1930 Federico García Lorca vivió en Nueva York como estudiante de la Universidad de Columbia. La estadía en Estados Unidos coincidirá con un período de intensa búsqueda de García Lorca respecto de la configuración de un lenguaje nuevo que le permitiera una expresión que trascendiera a las formas de escritura que hasta entonces había utilizado. Dicho período de búsqueda llegó a precipitarse debido, básicamente, a dos factores. Por un lado resultó fundamental el éxito de Romancero Gitano, publicado en 1928, cuando García Lorca no era aún el autor teatral consagrado por el gran público, ${ }^{1}$ éxito en el que más allá del reconocimiento, García Lorca leyó una señal peligrosa de encasillamiento como "poeta gitano" (Millán, 1995), inscripción o emplazamiento que no veía con agrado, pues podía significar un estancamiento de sus posibilidades de reinvención o exploración de perspectivas

\footnotetext{
${ }^{1}$ Como lo sería con posterioridad al estreno de Bodas de sangre en 1933.
} 
Me va molestando un poco mi mito de gitanería. Confunden mi vida y mi carácter. No lo quiero de ninguna manera. Los gitanos son un tema. Y nada más. Yo podía ser lo mismo poeta de agujas de coser o de paisajes hidráulicos. Además, el gitanismo me da un tono de incultura, de falta de educación y de poeta salvaje que no soy. No quiero que me encasillen. Siento que me van echando cadenas. NO (Obras Completas: LIX).

Por otro lado resultó fundamental su experiencia en la nueva estética de influencia surrealista, que había arraigado con fuerza en el contexto artístico español de finales de la década del 20 del siglo pasado (Millán, 1978), y de la que García Lorca tuvo conocimiento fundamentalmente a través de la vanguardia catalana, encabezada por Dalí y formada alrededor de la revista L' Amic de les Arts (Hernández, 2000; Sánchez, 1988). La estética de la vanguardia (en particular del surrealismo) reveló a García Lorca alternativas distintas de construcción poética, las que congeniaron con su necesidad psicológica de cambio y le abrieron (a pesar de que nunca acabó de adscribir a los principios surrealistas, al menos no a los que Bretón encerró en camisa de fuerza con la publicación de los manifiestos) ${ }^{2}$ un margen por donde llevar sus renovadas inquietudes (Millán, 1984). Es precisamente en la dirección de asumir una nueva estética y un renovado tratamiento del lenguaje que resultó fundamental el viaje de García Lorca a Nueva York, pues si bien es cierto que antes del viaje había incursionado ya en nuevas formas lingüísticas redactando algunas notables prosas poéticas (Como Santa Lucia y San Lázaro, Nadadora sumergida, Suicido en Alejandría, Degollación de los inocentes y Degollación del Bautista) y una pequeña obra teatral de 1925, El paseo de Buster Keaton (al que García Lorca veneraba al igual que a otros artistas del cine mudo, tales como Harold Lloyd o Chaplin), la nueva estética de García Lorca sólo se instalará de modo decisivo o adquirirá relevancia capital a partir del viaje a Nueva York. Recordemos que en 1930 García Lorca termina la primera redacción de la más transgresora, vanguardista y compleja de sus obras teatrales: El público (Millán, 1995). Parece ser evidente que Nueva York (la gran ciudad) le reveló a García Lorca nuevas dimensiones de sí mismo y sobretodo de su condición de poeta, las que requirieron e impusieron necesariamente un nuevo lenguaje para su adecuado tratamiento. García Lorca intuye en Nueva York la naturaleza problemática de la relación entre el poeta y la ciudad, ámbito irrenunciable desde Baudelaire, y dicha experiencia le impone un espacio que hasta entonces no había experimentado, pero al que debe descender y examinar. De ahí que en su conferencia Un poeta en Nueva York, Lorca enmiende, corrija: debió decir Nueva York en un poeta (García Lorca, 2004:43), es decir la

\footnotetext{
${ }^{2}$ Renegó siempre, por ejemplo, de que en sus trabajos más vanguardistas (como El público o Poeta en Nueva York) hubieran ejercicios de escritura automática, y en cambio aludió siempre a una estricta y cuidada lógica poética. En 1928, remecido ya por su necesidad de cambio y a propósito de unos poemas que envío a Sebastián Gasch, joven vanguardista catalán, escribe: "Son pura emoción descarnada, desligada del centro lógico, pero, ¡ojo!, ¡ojo!, con una tremenda lógica poética. No es surrealismo, ¡ojo!, la conciencia más clara los ilumina”. En García Lorca, F. (1972). Obras Completas. Madrid: Aguilar, 1654.
} 
interpretación interna de un mundo distinto, un lenguaje renovado a partir de la revelación de un espacio. García Lorca llegó a Nueva York en el momento cubista y futurista de exaltación de la gran ciudad, salvo por algunos cómicos del cine mudo y por el expresionismo alemán, en particular la película de Fritz Lang, Metrópolis (1927), que Lorca vio y asimiló con admiración en tanto denuncia de la ciudad mecanizada y esclavizadora (García-Posada, 2004), de ahí que su mirada de distancie del entusiasmo por el nuevo contexto urbano

Los dos elementos que el viajero capta en la gran ciudad son: arquitectura extrahumana y ritmo furioso. Geometría y angustia. En una primera ojeada, el ritmo puede parecer alegría, pero cuando se observa el mecanismo de la vida social y la esclavitud dolorosa de hombre y máquina juntos, se comprende aquella típica angustia vacía que hace perdonable, por evasión, hasta el crimen y el bandidaje (Nueva York en un poeta, 44).

La posición de García Lorca en Nueva York posibilitará, al mismo tiempo que desatar el lenguaje insinuado, construir o configurar un hablante que se instala como un observador crítico en un espacio urbano y desde esa lógica es que resulta pertinente proponer una lectura de Poeta en Nueva York desde el concepto de flâneur. Resulta fundamental, desde esa perspectiva, analizar previamente y con algún énfasis, las conceptualizaciones desarrolladas por Walter Benjamin (quién en efecto introduce el concepto, cuestión que lo posiciona como referente insoslayable en la materia) a propósito de Charles Baudelaire, para luego analizar el modo en que dichos conceptos aparecerían configurados en García Lorca.

2. PARÍS Y BAUDELAIRE: EL ORIGEN DEL FLÂNEUR COMO CONSTRUCTOR DE IDENTIDADES ESPECULADAS

Se fue el viejo París. (De una ciudad la forma ay, cambia más de prisa que un corazón mortal).

C. Baudelaire, El cisne.

El concepto de flâneur aparece vinculado al pensamiento de Walter Benjamin a propósito de lo moderno en la poesía de Baudelaire y el entorno urbanístico de París hacia mediados del siglo XIX (espacios y contextos que Baudelaire incorpora con insistencia en su producción, sobretodo en Pequeños poemas en prosa, que en efecto está imbuido del espíritu del flâneur desde lo temático y lo estructural), contexto en torno al cual Benjamin delimita y elabora el concepto a fin de configurar un elemento que permita la comprensión de la producción de Baudelaire en el momento de la modernización de París durante el Segundo Imperio (Benjamin, 1991). La experiencia de Baudelaire es la experiencia del artista frente a lo moderno y su correspondiente interpretación estética: su obra, en efecto, diseñó la disciplina y la espíritu de la modernidad estética que alcanzaría luego, con las vanguardias históricas, sólo su culminación (Habermas, 2004). Sin embargo y como bien ha hecho notar Morales (2002), más allá de las circunstancias históricas implicadas en su origen 
y la aparente circunscripción al trabajo de Baudelaire, la pertinencia y productividad crítica del concepto de flâneur salta a la vista proyectándose más allá de esas delimitaciones, esto es, más allá de Baudelaire y del París de mediados del siglo XIX, ofreciéndose como un elemento que puede resultar clave al momento de analizar la emergencia de lo urbano moderno en las construcciones literarias. De ahí que se proponga el análisis de Poeta en Nueva York en esa dirección. Sin embargo, por ahora el examen y esclarecimiento del concepto se guiará orbitando en torno al trabajo de Benjamin sobre Baudelaire en el cual se asoma como explícito y claramente identificable y rastreable, para en un momento posterior analizar cómo se aplica el concepto a las dimensiones estructurales y temáticas de los poemas que García Lorca escribió en Nueva York.

La relación entre la figura del flâneur y ciertos espacios urbanos es estrecha y fundamental. La palabra flâneur alude a una figura del contexto cotidiano, en la medida en que se trata de un sujeto que pasea, pero que pasea por un espacio delimitado y específico que es la calle (Benjamin, 1991). Esto hace patente su pertenencia exclusiva a la vida urbana, pues sólo en tales contextos adquiere pleno sentido y se configura propiamente (Morales, 2002; Muñoz Millanes, 1998). Tenemos, entonces, como primer elemento, que el flâneur es una figura eminentemente urbana. Pero además es una figura que pertenece a espacios urbanos claramente delimitables. Se vincula a los espacios urbanos modernos occidentales, y por lo tanto su aparición termina de definirse en la primera mitad del siglo XIX, pues entonces es que se producen las trasformaciones urbanísticas en el espacio europeo que permitirán las condiciones físicas espaciales para que el flâneur pueda deambular por la ciudad

En París, por ejemplo, cumplen esa función las innovaciones introducidas por el proyecto urbanístico de Haussmann, que trajeron consigo la apertura de nuevas vías de circulación: así, los bulevares, comunican sectores urbanos o barrios, hasta entonces más o menos desconectados entre sí o cerrados sobre sí mismos, espacios que comunican una calle con otra” (Morales, 32).

El flâneur y su configuración en Baudelaire, en efecto, no pueden entenderse si no se comprenden las drásticas transformaciones que está sufriendo la ciudad de París hacia mediados del siglo XIX, durante el imperio de Napoleón III, y cuyo responsable fue el político y urbanista George Eugène Haussmann. ${ }^{3}$ Los objetivos y necesidades de estas transformaciones fueron múltiples y complejas: la necesidad técnica de espacios regulares que permitieran la implantación de modernas instalaciones urbanas, necesidades de tráfico y de vivienda, entre otras. Pero sin lugar a dudas, una de las necesidades más relevantes en la metamorfosis de París, tuvo que ver con la

\footnotetext{
${ }^{3}$ Estas transformaciones urbanísticas y sus implicancias sociales aparecen retratadas también por Émile Zola en algunas novelas de su serie Los Rougon-Macquart, que es precisamente, y como subtitula Zola, "la historia natural y social de una familia bajo el Segundo Imperio en Francia”.
} 
posibilidad de garantizar ciertas ventajas militares que permitieran contener eventuales movimientos revolucionarios (George, 1969). Es, en ese contexto, que se urbaniza la periferia de París y se abren calles anchas y rectilíneas que impidan, por ejemplo, los ejercicios de resistencia y barricada. Con ese objetivo es que no se dudó en derribar extensas áreas del París medieval, en especial aquellas que más habían destacado en la resistencia revolucionaria. La transformación de París estuvo por tanto profundamente influida por el temor a la resistencia del golpe de Estado de $1851,{ }^{4}$ y debe visualizarse como un mecanismo o tecnología de control social, una especie de ejercicio arquitectónico y urbanístico disuasivo, en la medida en que el diseño de la ciudad se dirigía hacia la urgencia de hacer "visible” al transeúnte. Para ello se abren las calles de manera que no pudieran generarse desde ellos movimientos de revolución o resistencia. Es una suerte de ejercicio para convertir a la ciudad en un "panóptico", 5 espacios que garantizaran la visibilidad absoluta de los transeúntes, hecho que por sí mismo regulara su conducta al sentirse expuestos y vigilados, debido a la relación íntima existente entre las tecnologías de poder y la densidad que adquiere un espacio como zona de incorporación de los cuerpos a una mecánica de subjetivación (Castro, 2009). Se trata de generar en el contexto del Segundo Imperio en Francia espacios urbanos que, de acuerdo a las conceptualizaciones de Foucault, faciliten el control de los cuerpos y la introducción de dispositivos disciplinarios, áreas en las que la inspección funcione sin cesar y la mirada esté por doquier en movimiento (Foucault, 2006). La intervención de Haussmann en París pretendió en gran medida, por lo tanto, generar un espacio donde la mirada se multiplicara y disuadiera. Pues bien, tal como examina y sugiere Benjamin (1991), son estas transformaciones las que generaron los espacios que condicionaron y permitieron la aparición del flâneur, en la medida en que ellos facilitaron su deambular y las condiciones que estos ejercicios requieren. El paseante o caminante encuentra a su paso espacios abiertos que le permiten desplazarse de una calle a otra, circular por distintos sectores urbanos y bulevares, y de ese modo abocarse a su principal ocupación: observar. Aquello que el flâneur observa, desde su particular sensibilidad, es la irrupción de una reconversión social asociada a la transformación arquitectónica: la transformación urbana de París, sobretodo la apertura de bulevares anchos y largos e interconectados, permitió, al mismo tiempo que permite deambular al flâneur, la

\footnotetext{
${ }^{4}$ Recuérdese que luego de que Luis Felipe I fuese derrocado a raíz del triunfo de la Revolución de 1848, Luis Bonaparte (luego Napoleón III) se presentó como candidato a la presidencia de la recién constituida II República Francesa, obteniendo una mayoría abrumadora. Sin embargo, derrotas en las elecciones legislativas de 1849 y la imposición constitucional que limitaba su período sólo a cuatro años, impulsaron a Luis Bonaparte a que diera un golpe de estado en diciembre de 1851 que le permitió asumir poderes dictatoriales y ampliar su período a diez años.

${ }^{5}$ Edificio diseñado por J. Bentham en el siglo XVIII para ser implementado en prisiones y cuyo objetivo era inducir en el detenido un estado consciente y permanente de visibilidad que garantizara el funcionamiento automático del poder. El detalle de la estructura puede encontrarse en M. Foucault. Vigilar y Castigar. Buenos Aires: Siglo XXI Editores, 2006.
} 
irrupción en el paisaje urbano del fenómeno de la multitud. Se trata de un conjunto anónimo, disgregado, ajeno a la idea comunitaria de sociedad y que se apodera de estos espacios nuevos que permiten amplios desplazamientos y que inauguran nuevas modalidades de interacción

Ya el hormigueo de las calles tiene algo de repugnante, algo en contra de lo cual se indigna la naturaleza humana (....). La indiferencia brutal, el aislamiento insensible de cada uno de sus intereses privados, resaltan aún más repelente, hiriente, cuanto que todos se aprietan en un pequeño espacio (Engels en Benjamin, El país del Segundo Imperio, 74).

Es precisamente esa indiferencia brutal y aislamiento insensible que Engels detecta en las calles de Londres, el que otorga anonimato al flâneur, para deambular por la ciudad y abocarse a sus ejercicios de rastreo y observación. La multitud le sirve como refugio para ello. Como hemos dicho se trata de una multitud ajena a cualquier idea de sociedad como comunidad, desgarrada como unidad y que aparece como espectro, convertida en una sociedad moderna, es decir adviene como artefacto o constructo. Esto es, multitud como grupo humano que comparte espacios, pero que no responde a raíces o motivaciones comunes, construida artificialmente como sociedad o grupo. Es decir, y de acuerdo a las elaboraciones de B. Anderson, se trata ya de una comunidad imaginada (Anderson, 1991).

Charles Baudelaire es testigo privilegiado de las transformaciones urbanísticas que tienen lugar en París promediado el siglo XIX, y recogió este hecho en varios de sus textos, expresando el efecto negativo que esos cambios provocaron en él e intuyendo los que provocarían y provocaban en la ciudad como espacio, y desde luego en sus habitantes. En los "Ojos de los pobres" alude precisamente a uno de los bulevares del diseño Haussmann, nuevo o en construcción, lleno de escombros y que ya exhibe su esplender inacabado, ${ }^{6}$ y en "El cisne" de Las Flores del mal alude al aura que pierde País irremediablemente bajo el influjo de sus transformaciones urbanas

¡París cambia, mas nada en mi melancolía se ha movido! Andamiajes, palacios, horizontes, viejos barrios, ya todo se me hace alegoría...

¡Son mis caros recuerdos más pesados que montes! (Baudelaire, 139-140).

Baudelaire deambula por París y en sus textos configura el hablante poético que Benjamin conceptualiza a través de la figura del flâneur: Baudelaire es, en efecto, el flâneur de París, que asume respecto de las transformaciones de las que está siendo testigo, una distancia crítica. Comparte el espacio de la multitud, valiéndose del anonimato del que goza al atravesar la ciudad, observa y examina desde una postura crítica. Es precisamente esa postura la que lo separa y distingue de la masa, imponiéndole una natural distancia entre él y la muchedumbre

\footnotetext{
${ }^{6}$ Baudelaire, C. (1997). “Los ojos de los pobres”, en Pequeños Poemas en Prosa. Traducción y notas de Enrique López Castellón. Madrid: M. E. Editores, 146.
} 
No albergo convicciones, tal como las entienden las gentes de mi época, porque carezco de ambición. En mi no existe base para una convicción (....).No obstante, tengo determinadas convicciones, en un sentido más elevado, que no pueden ser comprendidas por las gentes de mi época (Baudelaire, Obras, 689).

Baudelaire se siente inmerso en una masa indiferente no sólo a su producción literaria, sino también a su propia experiencia. En la vorágine de la gran ciudad las relaciones han perdido todo matiz afectivo. En este contexto la figura del flâneur debe afrontar la paradoja de estar estructurado entre la soledad y la multitud y su dependencia de ambas circunstancias: requiere del aislamiento como requisito en su condición de observador, pero al mismo tiempo requiere de los espacios donde se desenvuelve la multitud para ejercer tal condición. Esto lo sitúa en una paradoja: desprecia a las multitudes ("hay personas que no pueden divertirse más que en tropel, el verdadero héroe se divierte absolutamente solo") ${ }^{7}$ pero son su objeto de observación. El flâneur huye de la mirada del otro, pero necesita imponer su mirada sobre la multitud y perderse para ello en la masa anónima. Con la superioridad psicológica que siente el que observa sin ser visto, el poeta dirige su mirada sobre la multitud que hormiguea por los laberintos de la metrópoli, buscando e indagando en la multitud, señales, signos que le permitan configuran sentidos en medio de la multitud desgarrada y articular rastros de la comunidad desvanecida. El deambulador parisiense, el paseante solitario, adopta por tanto una actitud de observación, pues "en determinados estados del alma casi sobrenaturales, la profundidad de la vida se revela por entero en el espectáculo, por irrelevante que sea, que uno tiene ante sí” (Raymond, 17). Desde luego que la mirada del flâneur no es una mirada pasiva, neutra, sólo registradora, ni tampoco una mirada meramente curiosa, sino es una mirada que examina y que funciona de acuerdo a un principio activo de selección y construcción

El movimiento comienza cuando algún transeúnte azaroso entra en el foco de la mirada y ésta se detiene, inquisitiva, en determinados detalles de la vestimenta del rostro o de la gestualidad. A la mirada del flâneur, tales detalles se trasforman en signos. En un primer momento, signos con un significado más bien residual, difuso opaco, dispersos, incapaces ya de hacer transparente una identidad (la del otro). En un segundo momento, la imaginación del flâneur hace de ellos signos de una identidad ahora especulada, construida (Morales, 34).

La tarea del flâneur consiste en extraer lo eterno de lo transitorio, de la escena fugaz del personaje que sólo se cruzará una vez en su camino (López Castellón, 1997). De ahí que en su condición de observador esté atento al momento en que algún transeúnte asome en su foco de mirada: Pensemos en "Las viejecillas”: “Ah, cuántas he seguido de esas pequeñas viejas/ Una entre otras, a la

\footnotetext{
${ }^{7}$ Baudelaire, C. (1997). Ob. Cit., 113.
} 
hora en que el sol declinante/ ensangrienta el espacio con heridas bermejas, / pensativa sentábase en un banco distante" ${ }^{8}$ Pensemos en "A una transeúnte", 9 texto en el que explícitamente se alude al transeúnte que entra en el foco de la mirada del flâneur, que lo atrapa pasajeramente y del cual extrae signos dispersos y difusos. La tarea del flâneur reside precisamente en ello: debe rastrear fragmentos, rastros dispersos que configura y reconstruye como signos hasta dar una forma a una identidad especulada, es decir ya no aprehensible como unidad más que como especulación. El objetivo es leer signos residuales a partir de las rutinas urbanas para construir con ellos identidades. Se sugiere así una posición posmoderna: sujetos e identidades construidos a partir de fragmentos. Precisamente la ida de recabar significados dispersos deriva del sentimiento de pérdida de unidad del sujeto tal éste como había sido concebido hasta el siglo XIX, acontecimiento que se encuentra vinculado a la desintegración de la sociedad como comunidad y convertida en artefacto. Es, debido a ese motivo, que las construcciones de signos de identidad no pueden adoptar la forma de una línea continua o ininterrumpida. Esta continuidad está impedida o restringida, y debido a eso, en la sociedad moderna construida como artefacto, el flâneur puede ocuparse sólo de estímulos dispersos, erráticos e intermitentes. Los vínculos comunitarios han sido sustituidos por la mera adición de individuos (Morales, 2002), y debido a eso lo único rastreable son elementos dispersos. Por eso la observación del flâneur ejecuta sobre una mirada interrumpida, que ciertamente es fragmentaria, de ahí que la obra solo pueda adquirir una estructura inorgánica, a partir de la cual cada una de las partes se retrotrae como unidad, pero no como unidad propiamente, sino como artefacto. En esta modalidad de construcción, Baudelaire está anticipándose a la estética fragmentaria de las vanguardias históricas (Morales, 2002) que propondrán precisamente una obra que expulsa de sí la continuidad y linealidad y que se construye desde un orden fragmentario. Eso es precisamente lo que intenta el flâneur como observador privilegiado: la construcción de signos de identidad (como especulación) donde sólo hay signos dispersos (Morales, 2002).

Baudelaire percibe que la era industrial y la implantación del espíritu burgués significan e implican un síntoma inconfundible de que la cultura occidental ha iniciado un declive. Desde esa lógica el flâneur es la voz del corifeo, la del actor solitario de la tragedia antigua por cuya boca se hace presente el coro enmudecido. Todas las voces de una gran ciudad, todos los gritos de esas vastas prisiones del final de las culturas donde la vida se vuelve casi absolutamente insoportable (Lamarque, 1997). Esta decadencia que Baudelaire percibe y recepciona produce un efecto inmediato en su sentimiento estético (López Castellón, 1997) y la consiguiente predilección y proximidad del flâneur por temas, escenarios y

\footnotetext{
${ }^{8}$ Baudelaire, C. (1997). Las flores del mal. Traducción de Nydia Lamarque. Buenos Aires: Losada. 144-145.

${ }^{9}$ Baudelaire, C. (1997). “A una transeúnte”, en Las flores del mal. Traducción de Nydia Lamarque. Buenos Aires: Losada, 147.
} 
personajes específicos, que vienen a representar la resistencia o la marginalidad frente al nuevo orden social que se impone, de ahí que no son extrañas las afinidades que el flâneur experimenta por sujetos marginales que de alguna manera "resisten" (o son victimas) del nuevo orden y por eso congenian con el flâneur que los rescata, al menos con la mirada, de la multitud anónima en la que se hallan extraviados. Se trata de sujetos que quedan, de acuerdo a la lectura de F. Doltó, precisamente al margen del nuevo París de Haussmann, lejos de las transformaciones urbanísticas o circunscritos a espacios marginales antes no distinguidos. No tienen espacios en el París que se diseña durante el Segundo Imperio, al contrario, la nueva estructura los invisibiliza (Doltó, 1996).

Asociado a las transformaciones urbanísticas de París, Benjamin analiza además otro aspecto de la experiencia del flâneur: el shock (Benjamin, 1999). En un contexto urbano moderno en el que la multitud enfrenta una secuencia de estímulos derivados de la transformación de la ciudad, el advenimiento de formas arquitectónicas que facilitan la multiplicación de los estímulos, y la propia coexistencia de la multitud (que, forzosamente, requiere de nuevas modalidades de socialización), los sujetos se anestesian, en su experiencia urbana a la proliferación y experimentación de estímulos, de manera que no son capaces de "percibir" los signos que esas transformaciones deparan a la sociedad íntegra. Esa, termina siendo, una facultad privativa del flâneur. Para analizar estas cuestiones, Benjamin recurre a algunas conceptualizaciones expresadas por Sigmund Freud en Más allá del principio del placer (1920). En dicho texto Freud expresa algunas consideraciones a partir de sus distinción nosológicas de los sistemas o estructuras mentales y plantea que el sistema consciente no es capaz de guardar huellas anémicas, éstas, deben ser necesariamente propiedad exclusiva de otra estructura o sistema (el inconsciente), debido a que la conciencia debe ejercer una especie de vigilancia sobre los estímulos que se reciben y así resguardan que éstos no se filtren libremente hasta estructuras profundas, pues eso ocasionaría un shock (Freud, 1994). Para cumplir esa función, plantea Freud, el sistema consciente sacrifica su sensibilidad, de modo que determinados estímulos ya reconocidos por la conciencia no generen dificultades en estructuras psíquicas más profundas (Freud, 1994). Benjamin, rescata estos conceptos para aplicarlos a la experiencia del flâneur, y supone que la multitud de la ciudad en la que coexiste el flâneur, está anestesiada ante los estímulos debido a una convivencia ciega y recurrente con ellos. Esto impide, por ejemplo, que a partir del devenir urbano puedan constituirse experiencias, debido a que éstas requieren forzosamente traspasar un umbral consciente y anidarse en estructuras psíquicas profundas (Benjamin, 1999). Pero la multitud está impedida de generan dichos procesos pues mantiene una relación autómata con el contexto urbano, donde ningún ejercicio traspasa ese umbral consciente que "previene" el shock. En ese contexto, la multitud es incapaz de reflexionar a partir de las transformaciones que sufre el contexto urbano, no es 
capaz de encontrar en ellas señales y elaborar signos, sólo tropieza con fragmentos, residuos que al no dejar rastro mnémico se interpretan siempre aisladamente y ya no logran constituirse como experiencias. El flâneur, en cambio, enfrenta los estímulos sin resistencias y enfrenta el shock pues éste le permite una iluminación de la vida cotidiana y sobretodo una percepción adecuada de lo que la transformación de la ciudad implica. Desde esa perspectiva el flâneur, a diferencia de la multitud, se enfrenta sin anestesia a los estímulos urbanos y a pesar de que las transformaciones de la ciudad son complejas para su estado anímico, insiste en enfrentar a la ciudad y revelar sus signos. La experiencia urbana deja en él huellas mnémicas trascendentes, pues a partir de dichas huellas es que puede constituirse como constructor de signos y de identidades, aunque éstas sean parciales, fractales.

Con esto hemos revisado las nociones básicas para la comprensión del concepto de flâneur a partir de su configuración en Baudelaire.

\title{
3. EL FLÂNEUR EN NUEVA YORK
}

\author{
"Nosotros, las civilizaciones, sabemos ahora que \\ somos mortales" Paul Valéry.
}

Veamos pues, a continuación, si es admisible considerar que se convocan en Poeta en Nueva York (y de qué forma) los elementos que permiten configurar la figura del flâneur. Las condiciones, como ha sido visto, son al menos las siguientes: debe tratarse de una figura del devenir cotidiano moderno tal como éste se desarrolla en las ciudades europeas a partir de mediados del siglo XIX cuando se instala la idea de multitud. Dicha subjetividad debe pasearse por espacios públicos con una conciencia y ocupaciones distintas a la de la multitud y revelar un esfuerzo o capacidad de construir, desde una lógica fragmentaria, signos de identidad en un momento en que lo que se asoma es la pérdida de la unidad del sujeto (y de la sociedad como comunidad).

La subjetividad construida en Poeta en Nueva York está instalada ciertamente en un espacio de corte urbano. Es cierto que en el entramado del libro, se consignan desplazamientos hacia Newburg y Vermont rastreables en los apartados del libro En la Cabaña de Farmer e Introducción a la muerte, ${ }^{10}$ no obstante es lo urbano lo que predomina en los textos. Abundan y son claramente identificables las alusiones claras y unívocas a ese espacio: Harlem, Bronx, Brooklyn, Manhattan, la torre del Chrysler Building, etc. Tenemos por tanto la condición primordial que permite la existencia del flâneur: un espacio urbano, occidental y moderno. Se requiere además para configurar o reconocer la figura del flâneur, que la subjetividad que lo representa se desplace por el espacio urbano en que se sitúa sin más ocupación que la propia contemplación. La idea de desplazamiento es claramente identificable en Poeta en Nueva York. García Lorca

${ }^{10}$ García Lorca, F. Poeta en Nueva York. Barcelona: Editorial de Bolsillo, 2004:87-103. 
alude literalmente a un paseo que se inicia en la Columbia University y que lo lleva a Harlem y de Harlem a Wall Street, y luego a Brooklyn, etc. Es decir, existe un sujeto se desplaza por un espacio moderno y urbano y que mientras se desplaza intenta configurar una unidad a partir de los fragmentos que contempla. Resulta evidente que la principal ocupación del sujeto que pasea por Nueva York es la de contemplar la ciudad y elaborar un registro de dicha contemplación. La estadía de García Lorca en Nueva York es el momento cubista y futurista de la exaltación de la ciudad, sin embargo, su mirada no exalta, sino que está marcada por el escepticismo. Del mismo modo y tal como es rastreable en relación a Baudelaire y París, la experiencia de García Lorca en Nueva York está marcada por la paradoja soledad/multitud. García Lorca intuye que la multitud que se desplaza por las calles neoyorquinas es un grupo informe, ajeno a toda idea de comunidad:

Y la multitud. Nadie puede darse cuenta exacta de lo que es una multitud neoyorquina (...). Coney Island es una gran feria a la cual los domingos de verano acuden más de un millón de criaturas. Beben, gritan, comen, se revuelan y dejan del mar llenos de periódicos y las calles abarrotadas de latas, de cigarros apagados, de mordiscos, de zapatos sin tacón. Vuelve la muchedumbre de la feria cantando y vomita en grupos de cien personas apoyadas sobre las barandillas de los embarcaderos, y orina en grupos de mil en los rincones, sobre los barcos abandonados y sobre los monumentos de Garibaldi o el soldado desconocido" (Nueva York en un poeta, 49). ${ }^{11}$

Pero a pesar del desprecio que Lorca experimenta por la multitud, algo le impele a deambular en medio de los espacios que ella desborda. Por un lado se trata, desde luego, de una íntima experiencia de soledad. Obsérvese en efecto que la primera parte de Poeta en Nueva York se llama precisamente "Poemas de la soledad en Columbia University”, ${ }^{12}$ y nótese como caracteriza Lorca su experiencia personal en la ciudad estadounidense

Nadie puede darse idea de la soledad que siente allí un español y más todavía si éste es hombre del sur. Porque, si te caes, serás atropellado, y, si resbalas al agua, arrojarán sobre ti los papeles de las meriendas (Nueva York en un poeta, 49).

Yo, solo y errante, agotado por el ritmo de inmensos letreros luminosos del Times Square, huía en este pequeño poema del inmenso ejército de ventanas donde ni una sola persona tiene tiempo de mirar una nube o dialogar con una de esas delicadas brisas que tercamente envía el mar sin recibir jamás una respuesta (Nueva York en un poeta, 45).

Pero al mismo tiempo que la soledad que se experimenta en la ciudad, lo que impulsa al flâneur de Nueva York a deambular por los espacios que invade la multitud está íntimamente vinculado con el hecho de buscar signos de significado

\footnotetext{
${ }^{11}$ Véase también, García Lorca, F. Ob. Cit. "Paisaje de la multitud que vomita”, y "Paisaje de la multitud que orina”, 2004:73-76.

${ }^{12}$ García Lorca, F. Ob. Cit., 2004:57.
} 
residual, opaco y disperso con los cuales construir identidades fragmentarias, especuladas. El paseo de García Lorca por Nueva York está, en efecto, registrado desde la interrupción. La mirada del paseante de Nueva York, tal como la mirada de Baudelaire en París, está marcada por la lógica del corte, aún con mayor énfasis inclusive. Se trata de fragmentos de visiones, como si se tratara de diapositivas o fotografías de Nueva York. La ciudad está "retratada" a partir de dichos fragmentos, como si se tratara de un montaje. En este punto resulta evidente que García Lorca está influido por la estética de las vanguardias históricas, en donde la totalidad es sólo un montaje de fragmentos. El principio que sostiene la mirada del flâneur de Nueva York es por lo tanto un principio alegórico, en la medida en que se trata de crear sentido al reunir elementos aislados y fragmentarios de realidad. Como señala Bürger (1987), se trata de un sentido dado que no resulta del contexto original de los fragmentos, pero que por medio de un ajuste de los mismos permite una fijación de sentido. Se expulsa de la obra la continuidad y linealidad, constituyéndose un orden fragmentario, que se construye como collage a partir del montaje como principio artístico. Pues bien, evidentemente el observador de Poeta en Nueva York configura una estructura fragmentaria., donde los signos de identidad (por tanto la noción de sujeto) se considera una construcción, el sujeto se debe entenderse entonces como un proceso de construcción dinámico y que está en permanente evolución, es decir, el self como ensayo, como elaboración constante, intento o una prueba que naturalmente excluyen toda conclusión, todo gesto cerrado sobre sí mismo, tanto en su desarrollo como en el punto de su corte. En otras palabras: la subjetividad no es, como existencia, sino ensayo, permanente ensayo, donde la constante lectura de sí misma permite configurar nuevas dimensiones. Más allá de la unidad de ese periplo o recorrido por la ciudad de Lorca que se inaugura en la Universidad de Columbia y termina con la huida de la ciudad, la estructura de la obra es evidentemente fragmentaria, lo que no quiere decir que no sea capaz de reflejar unidad. A medida que transita por Nueva York todo lo que el "paseante" ofrece son partes, cortes, fotografías. Son sólo instantes o momentos del paseo, como disparar un flash sobre Times Square, Riverside Drive, Park Avenue, East River, Brooklyn Bridge, y luego intentar armar un collage sobre esos fragmentos.

La lógica de la fragmentariedad es, desde luego, más brutal en Lorca que en Baudelaire. Debe recordarse en este punto que Baudelaire asiste a la modernización de una ciudad o espacio al que pertenece, es decir, asiste a la transformación. La cuestión es diferente en García Lorca pues el no pertenece a Nueva York, es una subjetividad trasplantada y en tránsito (es casi un turista, que observa la ciudad, sin embargo, con una mirada distinta a la que utilizaría un paseante temporal) puede decirse, por tanto, que se encuentra aún más indefenso frente al shock de lo que se encontraba Baudelaire mientras asiste a la transformación arquitectónica y sociales de Paris. García Lorca que además se enfrenta a una metrópoli del siglo XX enfrenta la multiplicidad de estímulos sin que su sistema consciente (siguiendo la 
lectura que Benjamin hace de Freud) esté quemado o parcialmente adaptado a los estímulos que deberá afrontar. Todo lo que encuentra a su paso, mientras deambula por Nueva York, traspasa las defensas de su conciencia y se registra como huella mnémica. Cada fragmento, cada residuo de identidad es capturado y de esa forma se intenta iluminarlo para intentar construir un boceto de unidad u organicidad.

Esta distinción puede explicar además otra diferencia entre el "paseante” de Nueva York y el París. Puede señalarse que, de alguna manera, en García Lorca sucumbe al shock y dicha experiencia articula de modo decisivo toda la experiencia en la ciudad. Lorca asimila la mecanización de la vida en la ciudad y se rebela ante la injusticia social, la organización del capitalismo y a la naturaleza escarnecida y aplastada (García-posada, 2004), y lo hace (más allá de la misma mirada sostenida en el fragmento, el corte y el montaje) de modo diferente a Baudelaire. El flâneur en Baudelaire posee una naturaleza algo distinta, recorre la ciudad con una actitud diferente que a veces limita con la displicencia, que es una actitud que García Lorca no consiente. Obsérvese, por ejemplo, "El extranjero", de Pequeños poemas en prosa: "Amo las nubes...las nubes que pasan...allá arriba...allá arriba, ¡las maravillosas nubes!" 13 Compárese con algunos versos de "Nueva York. Oficina y denuncia”, que aparecen en el texto de Lorca en el momento en que regresa, luego de una tregua, al espacio urbano

Existen las montañas. Lo sé.

Y los anteojos para la sabiduría.

Lo sé. Pero yo no he venido a ver el cielo.

He venido para ver la turbia sangre,

la sangre que lleva las máquinas a las cataratas

y el espíritu a la lengua de la cobra (Poeta en Nueva York, 104).

García Lorca ha viajado a Nueva York, podríamos decir, a enfrentar el shock, y a registrarlo, a denunciar la deshumanización de la vida urbana moderna

Yo denuncio a toda la gente

que ignora a la otra mitad,

la mitad irredimible

que levanta sus montes de cemento

donde laten los corazones (...) (Poeta en Nueva York, 105).

El flâneur de Nueva York denuncia activamente; ocurre en cambio, que en la configuración de Baudelaire la experiencia del flâneur está empapada de la lógica spleen. Es decir se trata de un observador que se ve dominado por la melancolía, el profundo malestar psicológico que asalta al individuo sin obligaciones laborales sometidas a un horario fijo, al sujeto ocioso y lúcido que experimenta el absurdo de la existencia, urgido por exigencias que no puede responder por falta de vigor psíquico y por el transcurrir inexorable del tiempo que va disminuyendo progresivamente las

\footnotetext{
${ }^{13}$ Baudelaire, C. Ob. Cit., 1997:97.
} 
posibilidades de actuar (López Castellón, 1997). Es el spleen de la metrópoli, pues como plantea Azúa (1978) en la naturaleza está todo por hacer; en la ciudad todo se ha hecho, es perfectamente aburrida, una fuente de spleen en sí misma. Sensación que invade al hablante de los poemas en prosa, pero que es muy distinta a la actitud de Poeta en Nueva York que es denuncia activa. Mientras en Baudelaire, por poner la cuestión en términos de "temperamento", el flâneur es melancólico, casi flemático, en García Lorca es colérico. Sucede además que debido a la naturaleza de "trasplantado", el "paseante" de Nueva York quiebra, de alguna manera, una de las lógicas íntimas del flâneur: no es una subjetividad que "registre" acciones comunes en la vida cotidiana moderna o simples rutinas urbanas, para él se trata de experiencias límites que vive desde la desesperación y angustia.

García Lorca observa en Nueva York la decadencia de la sociedad occidental, y destaca la injusticia social y la organización del capitalismo, y pone en manifiesto que todo lo que se exalta en la ciudad es expresión de decadencia. No es extraño entonces, que tal como sucedía en Baudelaire, sienta atracción por las minorías que el orden desplaza de modo más brutal. Se aprecia, desde luego, alusiones a la segregación de la homosexualidad y a los judíos, ${ }^{14}$ pero la minoría que de modo más evidente aparece retratada en el paseo por el flâneur configurado en Nueva York es la de los sujetos de raza negra. Uno de los primeros lugares que se visitan en el paseo es Harlem

Y me lanzo a la calle y me encuentro con los negros (...) Yo quería hacer el poema de la raza negra en Norteamérica y subrayar el dolor que tienen los negros de ser negros en un mundo contrario, esclavos de todos los inventos del hombre blanco y de todas sus máquinas, con el perpetuo susto de que se les olvide un día encender la estufa de gas o guiar el automóvil o abrocharse el cuello almidonado o de clavarse el tenedor en un ojo (Nueva York en un poeta, 46).

En efecto, la segunda parte de Poeta en Nueva York, llamada "Los negros" está íntegramente dedicada a la raza negra. En uno de los poemas, dice el paseante de Nueva York

¡Ay, Harlemi ¡Ay, Harlemi ¡Ay, Harlem;

No hay angustia comparable a tus rojos oprimidos, a tu sangre estremecida dentro del eclipse oscuro, a tu violencia granate, sordomuda en la penumbra, a tu gran rey prisionero, con un traje de conserje (Poeta en Nueva York, 65).

Paralela a su empatía y exaltación por la marginalidad, también está inscrita, a lo largo de todo el paseo, la crítica a la organización del capitalismo. Debe recordarse que García Lorca estuvo en Nueva York entre 1929 y 1930, es decir,

\footnotetext{
${ }^{14}$ García Lorca, F. Ob. Cit., 2004:106-108.
} 
alcanza a ser testigo del crac en Nueva York y del inicio de la Gran Depresión. ${ }^{15}$ Dedica versos brutales a Wall Street en "Danza de la muerte", ${ }^{16}$ y a propósito de la estatua que preside las operaciones de la bolsa, dice: "De la esfinge de la caja de caudales hay un hilo tenso/ que atraviesa el corazón de todos los niños pobres". ${ }^{17}$ Dice además en una conferencia

Lo impresionante por lo frío y cruel es Wall Street. Llega el oro en ríos de todas las partes de la tierra y la muerte llega con él. En ningún sitio del mundo se siente como allí la ausencia total del espíritu: manadas de hombres que no pueden pasar del tres y manadas de hombres que no pueden pasar del seis, desprecio de la ciencia pura y valor demoníaco del presente. Y lo terrible es que toda la multitud que lo llena cree que el mundo será siempre igual, y que su deber consiste en mover aquella gran máquina día y noche y siempre (Nueva York en un poeta, 48).

$\mathrm{Al}$ realizar su denuncia García Lorca no permanece en la marginalidad, ni en los espacios marginales. Una de las imputaciones que con más fuerza deja sentir el paseante de Nueva York a propósito de la marginalidad, segregación e injusticia social que encuentra a su paso, es realizada contra el Vaticano. No elige, sin embargo, cualquier lugar para realizar esa denuncia, para deslizar ese grito hacia Roma. La imputación se realiza desde la torre del Chrysler Building. Es decir, García Lorca elige una torre, forma arquitectónica que se había convertido ya entonces ciertamente en expresión del capitalismo por excelencia (Paquot, 2008), para descargar su ira frente al espectáculo de la ciudad deshumanizada. Dice, o grita entonces, el paseante de Nueva York

Pero el hombre vestido de blanco
ignora el misterio de la espiga,
ignora el gemido de la parturienta,
ignora que Cristo puede dar agua todavía,
ignora que la moneda quema el beso de prodigio y da la sangre del
cordero al pico idiota del faisán (Poeta en Nueva York, 111).

Este grito es lanzado poco antes de que García Lorca emprenda su huida de Nueva York, y resulta interesante comparar el Epílogo de Pequeños Poemas en Prosa con "Grito hacia Roma". Mientras en París Baudelaire sube a un monte, desde donde observa la ciudad por entero: "hospital, purgatorio, celda, infierno, prostíbulo; /donde

\footnotetext{
${ }^{15}$ Dice García Lorca: "Yo tuve la suerte de ver por mis ojos, el último crack en que se perdieron varios billones de dólares, un verdadero tumulto de dinero muerto que se precipitaba al mar, y jamás, entre varios suicidas, gentes histéricas y grupos desmayados, he sentido la impresión de la muerte real, la muerte sin esperanza, la muerte que es podredumbre y nada más, como en aquel instante, porque era un espectáculo terrible pero sin grandeza” (García Lorca, Nueva York en un poeta, 48).

${ }^{16}$ García Lorca, F. Ob. Cit. Barcelona: De Bolsillo, 2004:70-73.

${ }^{17}$ García Lorca, F. Ob. Cit., 2004:71.
} 
todo lo atroz como una flor florece", ${ }^{18}$ es decir desde un espacio marginal de la ciudad (más allá de erigirse como un punto de observación privilegiado), derrotista; el hablante de Poeta en Nueva York, elige una torre, símbolo capitalista y sube al edificio Crhysler y desde ahí lanza su grito. La experiencia shock desborda al flâneur Nueva York y lo impulsa a la cólera. Queda puesto de manifiesto que el paseante de Nueva York aprecia en el progreso una señal de decadencia, cuando en la Novena parte del texto, titulada "Huida de Nueva York", subtitula, "Dos valses hacia la Civilización”. ${ }^{19}$ Es, al salir de Nueva York, que intuye (paradójicamente en el momento en que la ciudad moderna se exalta como señal inequívoca de progreso) el retorno a la civilización.

\section{COMENTARIOS FINALES}

Resulta evidente que los elementos que configuran la figura del flâneur en Baudelaire y su experiencia parisina, se visualizan en Poeta en Nueva York de Federico García Lorca. En ambas experiencias se aprecia una figura del devenir moderno tal como éste se desarrolla en las grandes ciudades de Europa a partir de mediados del siglo XIX, cuando aparece la multitud. Se trata de subjetividades que se desplazan por los espacios en los que emerge la muchedumbre y que poseen la sensibilidad para capturar signos de identidad (especuladas) en un momento de ruptura de la unidad de la idea de sujeto y de las sociedades como comunidad. La vinculación de las experiencias descritas por García Lorca y Baudelaire (aunque se trate de momentos históricos distintos) no sólo acontece a nivel temático sino también a nivel estructural: en ambos, aunque ciertamente de modo más radical en Poeta en Nueva York, se intenta construir una unidad a partir de fragmentos, por medio de una lógica de corte o interrupción que vincula esas escenas por medio del montaje, es decir vislumbrando (en el caso de Baudelaire) y ejecutando propiamente (en el caso de García Lorca) los principios organizadores de la obra propios de las vanguardias históricas. En ambas experiencias, además, se aprecia la distancia crítica respecto de la concepción de progreso $^{20}$ al que se exponen París y Nueva York, durante el Segundo Imperio en el caso de Baudelaire y hacia la década del 30 del siglo XX en el caso de García Lorca.

Universidad Santo Tomás*

Escuela de Psicología

Héroes de la Concepción $N^{\circ} 2885$. (Chile)

renearay@gmail.com

\footnotetext{
${ }^{18}$ Baudelaire, C. Ob. Cit., 1997:206.

${ }^{19}$ García Lorca, F. Ob. Cit., 2004:117.

${ }^{20}$ Es interesante respecto de este aspecto, y a propósito de la proximidad de García Lorca al surrealismo (en particular o sobretodo en obras como Poeta en Nueva York, El público o sus poemas en prosa) citar la particular lectura de las vanguardias que propone G. Geirola, respecto de que al contrario de lo habitualmente creído, las vanguardias históricas no encarnarían lo "nuevo", sino una reacción ante lo "nuevo" (fascismo, industrialización, cultura de masas, progreso, etc.). Ver Geirola, G. (1995). "Confluencias y divergencias entre la poesía de vanguardia en Latinoamérica y la poesía surgida de la guerra civil española”. Revista Chilena de Literatura. № 47. 27-56.
} 


\section{BIBLIOGRAFÍA}

Anderson, B. Comunidades imaginadas. Reflexiones sobre el origen y la difusión del nacionalismo. México, DF: F. C. E., 1991.

Azúa, F. Conocer Baudelaire y su obra. Madrid: Dopesa, 1978.

Baudelaire, C. Obras. Traducción de Nydia Lamarque. Madrid: Aguilar, 1961.

Baudelaire, C. Pequeños poemas en prosa. Traducción de Enrique López Castellón. Madrid: M. E. Editores, 1997.

Baudelaire, C. Las flores del mal. Traducción de Nydia Lamarque. Buenos Aires: Losada, 1997.

Benjamin, W. "El país del Segundo Imperio en Baudelaire”. En Poesía y Capitalismo. Traducción de Jesús de Aguirre. Madrid, Taurus, 1997:49-83.

Benjamin, W. Sobre algunas consideraciones en Baudelaire. Buenos Aires: Editorial Leviatán, 1999.

Bürger, P. Teoría de la vanguardia. Barcelona. Península, 1987.

Castro, R. "La ciudad apestada. Neoliberalismo y postpanóptico". Revista de Ciencia Política. Santiago de Chile, V.29, $N^{\circ}$ 1, 2009:165-183.

Doltó, F. La causa de los niños. Barcelona: Paidós, 1996.

Foucault, M. Vigilar y Castigar. Nacimiento de la prisión. Buenos Aires: Siglo XXI Editores, 2006.

Freud, S. (1994). "Más allá del principio del placer" (1920). En Obras Completas. Traducción y notas de James Strachey. Buenos Aires: Amorrortu, 1994. Tomo XVIII, 1994:13-62.

Geirola, G. (1995). “Confluencias y divergencias entre la poesía de vanguardia en Latinoamérica y la poesía surgida de la guerra civil española”. Revista Chilena de Literatura. $N^{\circ}$ 47, 1995:27-56.

George P. Geografia Urbana. Barcelona: Ariel, 1969.

García Lorca, F. Obras Completas. Madrid: Aguilar, 1972.

García Lorca, F. Poeta en Nueva York. En Poesía Completa III. Barcelona: DeBolsillo, 2004:55-122.

García Lorca, F. “Un poeta en Nueva York”. En Poesía Completa III. Barcelona: DeBolsillo, 2004:41-53.

García-Posada, M. “La plenitud de la poesía lorquiana”. Prólogo a Poesía Completa III de Federico García Lorca. Barcelona: DeBolsillo, 2004:920.

Habermas, J. "Modernidad: un proyecto incompleto”. En Casullo, N., El debate modernidad-posmodernidad. $2^{\circ}$ edición ampliada y actualizada. Buenos Aires: Retórica, 2004:53-63.

Hernández, M. "Luis Buñuel y Federico García Lorca: documentos de una amistad”. En FGL, boletín De la Fundación Federico García Lorca. Año XIV. $N^{o}$ 27-28, 2000:167-178. 
Lamarque, N. "Realidad y leyenda de Charles Baudelaire”. En Las flores del mal. Traducción de Nydia Lamarque. Buenos Aires: Losada, 1997:7-41

López-Castellón, E. "Lectura ética de Pequeños poemas en prosa". En Pequeños poemas en prosa. Madrid: M.E. Editores, 1997:19-92.

Millán, M. C. En torno a la estética superrealista: algunos aspectos estilísticos de la Generación del 27. Tesis Doctoral. Universidad Complutense, Madrid, 1978.

Millán, M. C. Poeta en Nueva York de Federico García Lorca. Contexto y originalidad. Madrid: Taurus, 1984.

Millán, M. C. "Introducción a El Público de Federico García Lorca”. El público. Madrid: Cátedra Letras Hispánicas, 1995:9-115.

Morales, L. "El lugar del flâneur en la antipoesía”. Revista Atenea, $N^{\circ} 485$. Universidad de Concepción, Concepción, Chile, 2002:31-41.

Muñoz Millanes, J. "Fenomenología del flâneur". Modos y Afectos del fragmento. Valencia: Pre-textos, 1998:145-167.

Paquot, T. "El regreso de las torres". En Urbanismo. Arquitectura y Globalización. Selección de Artículos de Le Monde Diplomatique, $N^{\circ} 79$. Santiago de Chile: Editorial Aún creemos en los sueños, 2008:25-32.

Raymond, M. De Baudelaire al surrealismo. México, DF: F. C. E., 1961.

Sánchez Vidal, A. Buñuel, Lorca, Dalí: el enigma sin fin. Barcelona: Planeta, 1988. 